\title{
Metabolism of conjugated linoleic acids and 18:1 fatty acids by ruminal bacteria: products and mechanisms
}

\author{
Correspondence \\ R. John Wallace \\ john.wallace@abdn.ac.uk
}

Received 16 November 2009

Accepted 18 November 2009

\author{
Nest McKain, ${ }^{1}$ Kevin J. Shingfield ${ }^{2}$ and R. John Wallace ${ }^{1}$ \\ ${ }^{1}$ Rowett Institute of Nutrition and Health, University of Aberdeen, Bucksburn, Aberdeen AB21 9SB,
UK \\ ${ }^{2}$ Animal Production Research, MTT Agrifood Research Finland, Jokioinen, FI-31600, Finland
}

Cultures of ruminal bacteria known to metabolize unsaturated fatty acids were grown in medium containing $50 \mu \mathrm{g} \mathrm{ml}^{-1}$ of geometric and positional isomers of conjugated linoleic acid (CLA) or $18: 1$ fatty acids and $37.4 \%$ deuterium oxide to investigate the mechanisms responsible for fatty acid metabolism. Butyrivibrio fibrisolvens JW11 converted cis-9, trans-11-18:2 and trans-9, trans11-18: 2 to trans-11-18:1 as the main product, labelled at $C-9$, and metabolized trans-10,cis-12$18: 2$ to trans-10-18:1, labelled at C-13, and smaller amounts of trans-12-18:1 and cis-12-18:1. Butyrivibrio proteoclasticus P-18 did not grow in the presence of cis-9,trans-11-18:2 or trans10, cis-12-18:2, but grew in medium containing trans-9,trans-11-18:2, forming 18:0.

Propionibacterium acnes, a ruminal species that isomerizes linoleic acid to trans-10,cis-12-18:2, did not metabolize CLA isomers further. $B$. fibrisolvens metabolized small amounts of trans-10$18: 1$, trans-11-18:1 and cis-9-18:1, but the products formed were not detected. $B$. proteoclasticus, on the other hand, carried out substantial conversion of $18: 1$ substrates to $18: 0$. P. acnes hydrated cis-9-18:1 and trans-11-18:1 to $10-\mathrm{OH}-18: 0$, which was further oxidized to yield 10-O-18:0. The deuterium enrichment in the intermediates formed during incubations with 9,11 geometric isomers of CLA was about half that of the products from trans-10,cis-12 CLA and $18: 1$ isomers, suggesting that the reduction of 9,11 geometric isomers CLA by ruminal bacteria occurs via different mechanisms compared with the metabolism of other unsaturated fatty acids.

\section{INTRODUCTION}

There is increasing evidence that nutrition plays an important role in the development of chronic diseases in the human population, including cancer, cardiovascular disease, insulin resistance and obesity. Clinical and biomedical studies have provided a large body of data to indicate that excessive intakes of saturated fatty acids increase cardiovascular disease risk (World Health Organization, 2003; Mensink et al., 2003) and may lower insulin sensitivity, which is a key factor in the development of the metabolic syndrome (Nugent, 2004). Most of the 12:0 and 14:0 and a significant amount of $16: 0$ in the human diet cones from ruminant-derived foods, and therefore there is interest in altering the composition of milk fat, in particular, as part of nutritional approaches to preventing and reducing the economic and social impact of chronic disease. Targets for altering milk fatty acid

Abbreviations: CLA, conjugated linoleic acid; DMOX, 4,4-dimethyloxazoline; FAME, fatty acid methyl ester; MPE, moles \% excess; PUFA, polyunsaturated fatty acid.

Two supplementary figures are available with the online version of this paper. composition with the potential to improve long-term human health include decreasing the content of mediumchain saturated fatty acids and enhancing the concentrations of several bioactive lipids, including cis-9-18:1, trans11-18:1 and cis-9,trans-11-18:2 (Pariza, 2004; Bauman et al., 2005; Shingfield et al., 2008).

Following ingestion, lipids in the ruminant diet are released from structural components, hydrolysed, and the nonesterified fatty acids are released into the rumen, adsorbed onto feed particles and hydrogenated or incorporated directly into bacterial lipids (Harfoot \& Hazlewood, 1997; Jenkins et al., 2008). Characterizing the formation of intermediates and production of end products arising from the biohydrogenation of lipids in the rumen is central to attempts to enhance the nutritional attributes of ruminant milk fat. Biohydrogenation has been studied for many years, most recently in attempts to identify species that form isomers of conjugated linoleic acid (CLA) as transient intermediates during the metabolism of linoleic acid (cis9,cis-12-18:2) to 18:0 (Kim et al., 2002; Paillard et al., 2007; Wallace et al., 2006; Nam \& Garnsworthy, 2007) and the mechanisms responsible for CLA synthesis (Wallace 
et al., 2007). Isomers of CLA also serve as a substrate for reduction to 18:1 intermediates and 18:0 (Kepler et al., 1966; Harfoot \& Hazlewood, 1997).

The main microbes known to influence fatty acid metabolism in the rumen are the ciliate protozoa, which effectively accumulate unsaturated fatty acids (Devillard et al., 2006), at least partly by ingesting chloroplasts (Huws et al., 2009), and a small number of bacterial species with a high biohydrogenating activity. Butyrivibrio fibrisolvens is a rather diverse group of Gram-positive bacteria, all of which metabolize linoleic acid at many times the rate of other ruminal species (Polan et al., 1964; Maia et al., 2007). Only a small subgroup within the $B$. fibrisolvens grouping carries out the reduction of $18: 1$ fatty acids, particularly trans-11-18:1 to $18: 0$ (Wallace et al., 2006). This subgroup is now known as Butyrivibrio proteoclasticus (Moon et al., 2008), formerly Clostridium proteoclasticum (Wallace et al., 2006), which in turn is believed to be the same species as that isolated many years ago, named Fusocillus sp. (Kemp et al., 1975). Metabolism of linoleic acid by Butyrivibrio results in the formation of trans-11-18:1 and cis-9,trans-11-18:2 as major intermediates. The same is usually true in the mixed ruminal ecosystem, but under certain conditions trans-10-18:1 is formed via the reduction of trans-10,cis-12-18:2 or from the isomerization of cis-9-18:1 and represents the major biohydrogenation intermediate of the mixed ruminal ecosystem in vivo (Shingfield \& Griinari, 2007). Post-ruminal infusion experiments have established that trans-10,cis-1218:2 exerts anti-lipogenic effects in the lactating cow (Baumgard et al., 2000; Sæbø et al., 2005; Lock et al., 2006), with recent studies suggesting that trans-10-18:1 may also decrease mammary lipogenesis (Shingfield et al., 2009). Our studies indicate that Propionibacterium acnes may be responsible for the formation of trans-10,cis-12-18:2 (Wallace et al., 2006). The aim of the present study was to extend previous investigations on CLA formation (Wallace et al., 2007) using similar techniques to examine and elucidate the mechanisms responsible for the reduction of CLA isomers and $18: 1$, and to characterize the production of metabolic intermediates by pure strains of ruminal bacteria.

\section{METHODS}

Bacteria and growth conditions. Butyrivibrio fibrisolvens JW11 was originally isolated from sheep as a proteolytic species (Wallace \& Brammall, 1985). Butyrivibrio proteoclasticus P-18 is a recently identified 18:0-producing bacterium isolated from grazing sheep (Wallace et al., 2006); its previous name was Clostridium proteoclasticum, but it was renamed recently (Moon et al., 2008) in view of its clear genetic distance from Clostridium and proximity to Butyrivibrio. Propionibacterium acnes G449 was isolated from sheep in the same study (Wallace et al., 2006) and found to produce trans-10,cis-12$18: 2$ from linoleic acid. These ruminal bacteria are held in the culture collection maintained at the Rowett Institute. A type strain of P. acnes (DSM 1897) was obtained from the Deutsche Sammlung von Mikroorganismen und Zellkulturen $\mathrm{GmbH}$, Braunschweig, Germany. All transfers and incubations were carried out under $\mathrm{O}_{2}$-free $\mathrm{CO}_{2}$ at $39{ }^{\circ} \mathrm{C}$ in Hungate-type tubes (Hungate, 1969). Inoculum volumes were $5 \%(\mathrm{v} / \mathrm{v})$ of a fresh culture into $5 \mathrm{ml}$ of medium. The media used in these experiments were based on the liquid form of M2 medium (Hobson, 1969), and deuterium oxide and fatty acids $\left(50 \mathrm{mg} \mathrm{l}^{-1}\right.$ ) were added as described previously (Wallace et al., 2007). All bacteria were incubated at $39{ }^{\circ} \mathrm{C}$ until stationary phase was reached. With $B$. fibrisolvens and $B$. proteoclasticus, this occurred at times up to $96 \mathrm{~h}$, depending on the fatty acid substrate, while $P$. acnes was grown for $96 \mathrm{~h}$. Growth of bacteria was measured in triplicate from the increase in optical density at $650 \mathrm{~nm}$ of the control tubes using a Novaspec II spectrophotometer (Amersham Biosciences). A $1 \mathrm{ml}$ sample was removed for protein determinations and analysis of the enrichment in water. Thereafter, $100 \mu \mathrm{l}$ of 19:0 $\left(200 \mathrm{mg}^{-1}\right.$ in methanol) was added and tubes were stored at $-70{ }^{\circ} \mathrm{C}$ and subsequently freeze-dried. Fatty acid metabolism was assessed based on comparisons of fatty acid determinations in the inoculated medium containing fatty acids compared with uninoculated controls.

Fatty acids. trans-10,cis-12-18:2, cis-9,trans-11-18:2 and trans9,trans-11-18:2 were obtained from Universal Biologicals, Cambridge, UK, sourced from Matreya, Pleasant Gap, PA, USA. trans-11-18:1 and cis-9-18: 1 were purchased from Sigma-Aldrich, while trans-10-18: 1 was a gift from Frédéric Destaillats, Nestlé, Lausanne.

Fatty acid extraction and analysis. Extraction of total fatty acids was based on the method of Folch et al. (1957), with modifications (Waşowska et al., 2006). Fatty acid methyl esters (FAMEs) and 4,4dimethyloxazoline (DMOX) derivatives were prepared and analysed by gas chromatography-mass spectrometry (GC-MS) according to standard procedures as described previously (Waşowska et al., 2006). Enrichment in the $m / z(\mathrm{M}+1)$ and $(\mathrm{M}+2)$ isotopomers (molecular ion +1 and +2 , respectively) was determined by GC-MS (Wallace et al., 2007). Enrichment in water was determined by gas isotope ratio MS (Wallace et al., 2007). Oxygen-containing FAMEs were analysed by GC-MS, as follows. A gas chromatograph (model 6890, Agilent Technologies) equipped with a flame-ionization detector and linked to a quadrupole mass-selective detector (model 5973N) was fitted with a $30 \mathrm{~m}$ fused silica capillary column (i.d., $0.25 \mathrm{~mm}$ ) coated with a $0.25 \mu \mathrm{m}$ film of $100 \%$ polyethylene glycol (Zebron ZB-Wax Plus, Phenomenex). The total FAME profile in a $1 \mu \mathrm{l}$ sample at a split ratio of 20:1 was determined using a temperature gradient programme (initial temperature $80{ }^{\circ} \mathrm{C}$ for $1 \mathrm{~min}$; increased at a rate of $25 \mathrm{C}^{\mathrm{o}} \mathrm{min}^{-1}$ to $160{ }^{\circ} \mathrm{C}$, which was held for $3 \mathrm{~min}$, then increased at a rate of $1 \mathrm{C}^{\mathrm{o}} \mathrm{min}^{-1}$ to $190{ }^{\circ} \mathrm{C}$, then further increased at a rate of $10 \mathrm{C}^{\mathrm{o}} \mathrm{min}^{-1}$ to $230{ }^{\circ} \mathrm{C}$, held for $40 \mathrm{~min}$ ). Helium was the carrier gas, operated at constant pressure (14 p.s.i., $97 \mathrm{kPa}$ ) and

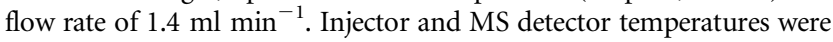
maintained at 250 and $230{ }^{\circ} \mathrm{C}$, respectively. Peaks were routinely identified by comparison of retention times with authentic FAME standards obtained from Sigma and Matreya. Identification was validated based on electron impact ionization spectra of FAMEs obtained under an ionization voltage of $2247 \mathrm{eV}$.

Data analysis. Results from replicate cultures $(n=3)$ were averaged and analysed by ANOVA. Least-square means \pm SE are reported and effects were considered significant at $P<0.05$. Enrichment of $\mathrm{M}+1$ and $\mathrm{M}+2$ isotopomers was calculated from the $\mathrm{m} / \mathrm{z}$ ratios at $\mathrm{M}$, $\mathrm{M}+1, \mathrm{M}+2$ and $\mathrm{M}+3$ by deconvolution according to Campbell (1974). Natural abundance was calculated from the isotopomer distribution of linoleic acid.

\section{RESULTS}

\section{Metabolism of CLA}

Three commercial samples of positional and geometric isomers of CLA in free fatty acid form were added to the growth medium of the four bacteria. None of these 
materials was of high purity as indicated from the analyses carried out on uninoculated medium (Tables 1 and 2). cis9, trans-11-18:2 was heavily contaminated with trans9, trans-11-18:2 (19.3 g per $100 \mathrm{~g}$ fatty acids) and lower amounts of cis-9,cis-11-18:2 (2.80) and trans-9,cis-11$18: 2$ (2.39). Similarly, the trans-9,trans-11-18:2-containing medium also contained trans-9,cis-11-18:2 (4.68 g per $100 \mathrm{~g}$ fatty acids) and cis-9,trans-11-18:2 (4.11). The trans10,cis-12-18:2 material was the least pure and also contained trans-10,trans-12-18:2 (28.7 g per $100 \mathrm{~g}$ fatty acids), cis-10,cis-12-18:2 (3.70) and cis-10,trans-12-18:2 (3.26). Although the fatty acids were added to a nominal concentration of $50 \mathrm{mg} \mathrm{l}^{-1}$, CLA concentrations detected were lower, the reasons for which were not established.

B. fibrisolvens converted cis-9,trans-11-18:2 and the contaminating trans-9,trans-11-18:2 almost completely to trans-11-18:1 (Table 1). The concentration of trans$18: 1$ formed corresponded to $92 \%$ of the cis- 9 , trans-11$18: 2$ and trans-9,trans-11-18:2 that were removed from the medium. In isolation, trans-9, trans-11-18:2 was metabolized less extensively, mainly to trans-11-18:1, while the mixture of trans-10,cis-12-18:2/trans-10,trans12-18:2 resulted in the production of trans-10-18: 1 and to a lesser extent trans-12-18:1 and cis-12-18:1. B. fibrisolvens did not reduce isomers of CLA to 18:0. B. proteoclasticus, on the other hand, was unable to grow in the presence of cis-9,trans-11-18:2 or trans-10,cis-12-18:2. Metabolism of trans-9,trans-11-18:2 resulted in the formation of $18: 0$, with only trace amounts of $18: 1$ intermediates (Table 2). No CLA was metabolized $(P>0.05)$ by either strain of $P$. acnes (results not shown).

\section{Metabolism of $18: 1$ fatty acids}

The 18:1 fatty acids used as substrates, trans-10-18:1, trans-11-18:1 and cis-9-18:1, were much purer than the CLA, with no evidence of major contaminants (Table 3). Also unlike the CLA, concentrations detected in the medium corresponded well to the concentration added. B. fibrisolvens removed $25-33 \%$ of these fatty acids from the medium (Table 3), but it was not possible to determine the products formed by GC-MS analysis. Although several small, generally broad peaks were visible, they were not suitable for integration, nor were they sufficient for MS analysis. In contrast, $B$. proteoclasticus converted substantial amounts of $18: 1$ substrates, cis-9-18:1 in particular, to $18: 0$. P. acnes DSM 1897 removed $29 \%$ of the trans-10$18: 1$, almost all the cis-9-18:1, but none of the trans-11$18: 1$, incubated. No $18: 0$ was formed. The main product was a fatty acid that eluted at $44.35 \mathrm{~min}$ on the Wax column, eluting before 10-OH-18:0 (47.83 min). The

Table 1. Metabolism of conjugated linoleic acids by $B$. fibrisolvens JW11

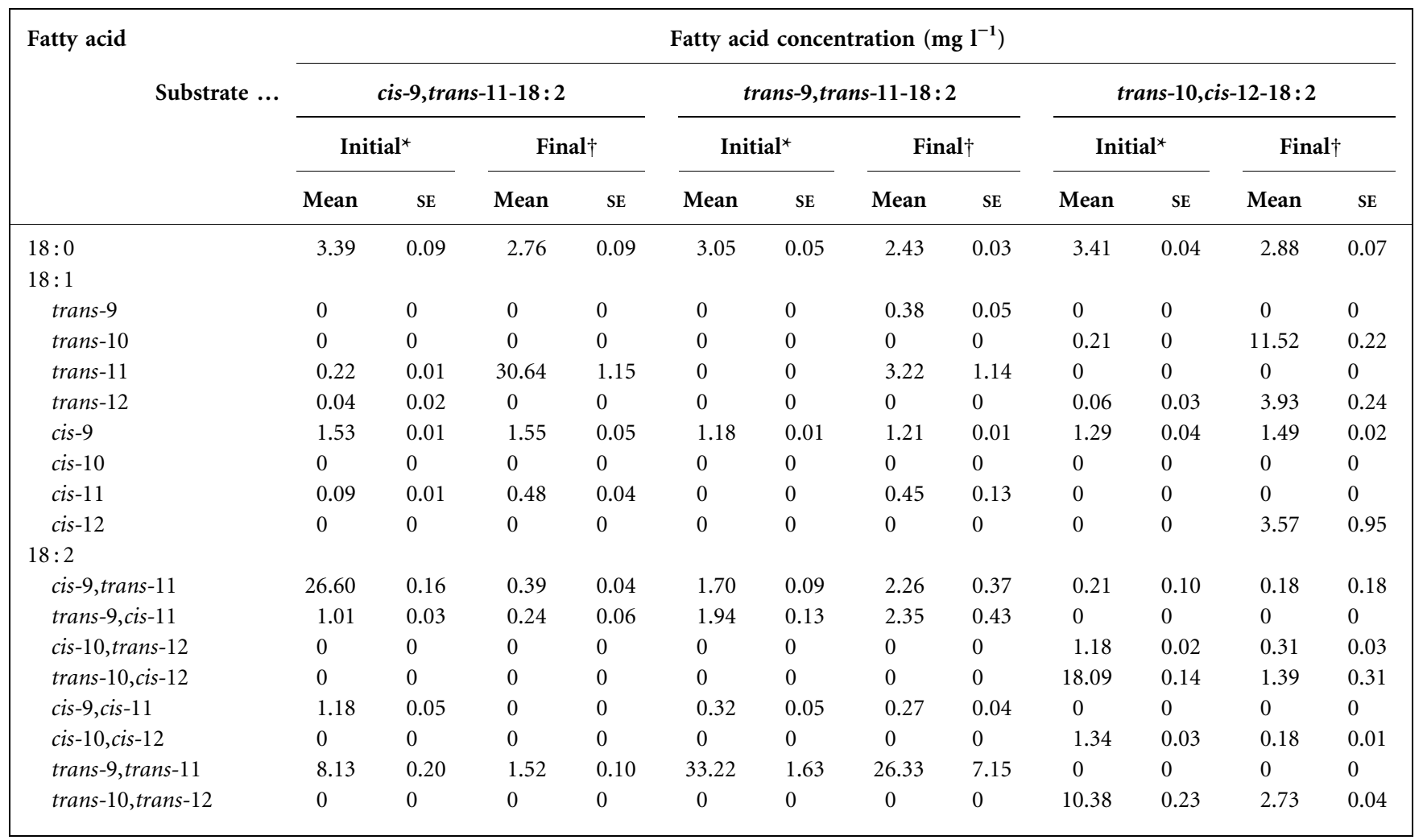

${ }^{\star}$ Uninoculated medium, $n=3$.

$\dagger$ Determined in $24 \mathrm{~h}$ cultures, $n=3$. 
Table 2. Metabolism of conjugated linoleic acids by $B$. proteoclasticus $\mathrm{P}-18$

No growth occurred with cis-9,trans-11-18:2 or trans-10,cis-12-18:2 in the medium.

\begin{tabular}{|c|c|c|c|c|}
\hline \multirow[t]{3}{*}{ Substrate ... } & \multicolumn{4}{|c|}{$\begin{array}{c}\text { Fatty acid concentration }\left(\mathrm{mg}^{-1}\right) \\
\text { trans-9, trans-11-18:2 }\end{array}$} \\
\hline & \multicolumn{2}{|c|}{ Initial $^{\star}$} & \multicolumn{2}{|c|}{ Final $\dagger$} \\
\hline & Mean & $\mathrm{SE}$ & Mean & $\mathrm{SE}$ \\
\hline $18: 0$ & 3.05 & 0.05 & 10.22 & 0.27 \\
\hline \multicolumn{5}{|l|}{$18: 1$} \\
\hline trans-9 & 0 & 0 & 0.23 & 0.04 \\
\hline trans -10 & 0 & 0 & 0 & 0 \\
\hline trans -11 & 0 & 0 & 0.39 & 0.03 \\
\hline trans -12 & 0 & 0 & 0 & 0 \\
\hline cis-9 & 1.18 & 0.01 & 1.22 & 0.03 \\
\hline cis-10 & 0 & 0 & 0 & 0 \\
\hline cis-11 & 0 & 0 & 0.24 & 0.02 \\
\hline cis-12 & 0 & 0 & 0 & 0 \\
\hline \multicolumn{5}{|l|}{$18: 2$} \\
\hline cis-9,trans-11 & 1.70 & 0.09 & 0.84 & 0.11 \\
\hline trans-9,cis-11 & 1.94 & 0.13 & 0.99 & 0.16 \\
\hline cis- 10, trans -12 & 0 & 0 & 0 & 0 \\
\hline trans -10, cis -12 & 0 & 0 & 0 & 0 \\
\hline cis-9,cis-11 & 0.32 & 0.05 & 0.14 & 0.07 \\
\hline cis-10,cis-12 & 0 & 0 & 0 & 0 \\
\hline trans -9, trans -11 & 33.22 & 1.63 & 26.95 & 2.93 \\
\hline trans -10, trans -12 & 0 & 0 & 0 & 0 \\
\hline
\end{tabular}

${ }^{*}$ Uninoculated medium, $n=3$.

$\dagger$ Determined in $30 \mathrm{~h}$ cultures, $n=3$.

electron impact spectrum (Supplementary Fig. S1) of the FAME indicated a molecular ion at $\mathrm{m} / z 312$ and an M-31 fragment at 281 consistent with an oxo-18:0 structure. Abundant ions at $\mathrm{m} / \mathrm{z} 141,171$ and 199 corresponding to cleavage alpha to the oxo group and the occurrence of fragments at $\mathrm{m} / \mathrm{z} 156$ and 214 formed by beta cleavage provided clear evidence of the location of the oxo group, allowing the product formed to be identified as 10-O-18:0. Interpretation was verified by cross-referencing with earlier reports that elucidated the structure of 10-O-18:0 based on GC-MS, FTIR spectroscopy and NMR analysis (Hou, 1994). Smaller amounts of 10-OH-18:0 were also produced from trans-10-18:1 and from cis-9-18:1 (Table 3). The rumen $P$. acnes isolate, G449, similarly metabolized no trans-11-18:1, but was less active than the type strain with cis-9-18:1, metabolizing about one-tenth of the initial concentration (results not shown). Product concentrations were too low for the structures to be identified.

\section{Labelling of products}

Mass spectra of methyl esters of the products formed during the metabolism of CLA and 18:1 substrates by $B$. fibrisolvens and $B$. proteoclasticus revealed three different patterns of incorporation of $\mathrm{D}$ from $\mathrm{D}_{2} \mathrm{O}$ (Table 4). trans11-18:1 produced from 9,11 geometric isomers of CLA was enriched in the $M+1$ isotopomer to about $25 \%$ moles $\%$ excess (MPE). In contrast, the $\mathrm{M}+1$ isotopomers formed during metabolism of 10,12 CLA isomers were labelled to 39.9-42.8\% MPE. None of the incubations with CLA yielded a labelled $\mathrm{M}+2$ isotopomer in the 18:1 products. Labelling of 18:0 resulting from the reduction of $18: 1$ substrates was $39.9-43.1 \% \mathrm{MPE}$ in $\mathrm{M}+1$ and $19.5-$ $23.8 \% \mathrm{MPE}$ in $\mathrm{M}+2$. No labelling was evident in the molecular ion from 10-O-18:0 derived from $P$. acnes incubations (Table 4). 10-OH-18:0 was found to be labelled in $M+1$ and $M+2$, as adjudged from ion fragments at $\mathrm{m} / \mathrm{z} 169$ and 201 due to the absence of a molecular ion.

The position of $\mathrm{D}$ atoms was investigated by examining mass spectra of DMOX esters. Enrichment of fragments of the DMOX derivative of trans-11-18:1 produced from 9,11 geometric isomers of CLA did not provide evidence for the location of the $\mathrm{D}$ label due to the low abundance of ion fragments in the C-10 $(\mathrm{m} / \mathrm{z}=224)$ region (Supplementary Fig. S2a). The mass spectrum of the DMOX derivative for trans-11-18:1 that was produced in even smaller amounts during incubations with trans9, trans-11-18:2 was even less clear (not shown). In contrast, the mass spectrum from trans-10-18:1 formed by the reduction of trans-10,cis-12-18:2 yielded more information, and revealed that the enrichment in $\mathrm{M}+1$ declined markedly between C-13 $(\mathrm{m} / \mathrm{z}=264)$ and C-12 $(\mathrm{m} / \mathrm{z}$ $=250$ ) (Supplementary Fig. S2b), indicating that the label was located, in the main, on C-13. Mass spectra of $18: 0$ produced as an end product were not informative about the location of $\mathrm{D}$ atoms (not shown).

\section{DISCUSSION}

Previous studies on the mechanisms responsible for the formation of CLA isomers in the rumen (Wallace et al., 2007) complemented earlier research carried out by ourselves and others to unravel the microbiology and biochemistry of the biohydrogenation process. Clear differences were identified between the mechanisms underlying the synthesis of cis-9, trans-11-18:2 and trans10,cis-12-18:2 from linoleic acid (Wallace et al., 2007), and also in the bacterial species that carry out the reactions. Here we provide analogous information on the subsequent metabolism of CLA isomers, revealing that there are also differences in the mechanism of reduction to $18: 1$ intermediates. The experiments were carried out with growing cultures of bacteria rather than cell suspensions, because active growth is required for biohydrogenation to occur (Wallace et al., 2006). Fatty acid metabolism during the lag phase is essential for Butyrivibrio spp. to escape the toxicity of unsaturated fatty acids (Maia et al. 2007). Further metabolism occurs in the exponential phase, but no further transformations occur during the stationary 
Table 3. Metabolism of $18: 1$ fatty acids by ruminal bacteria and $P$. acnes DSM 1897

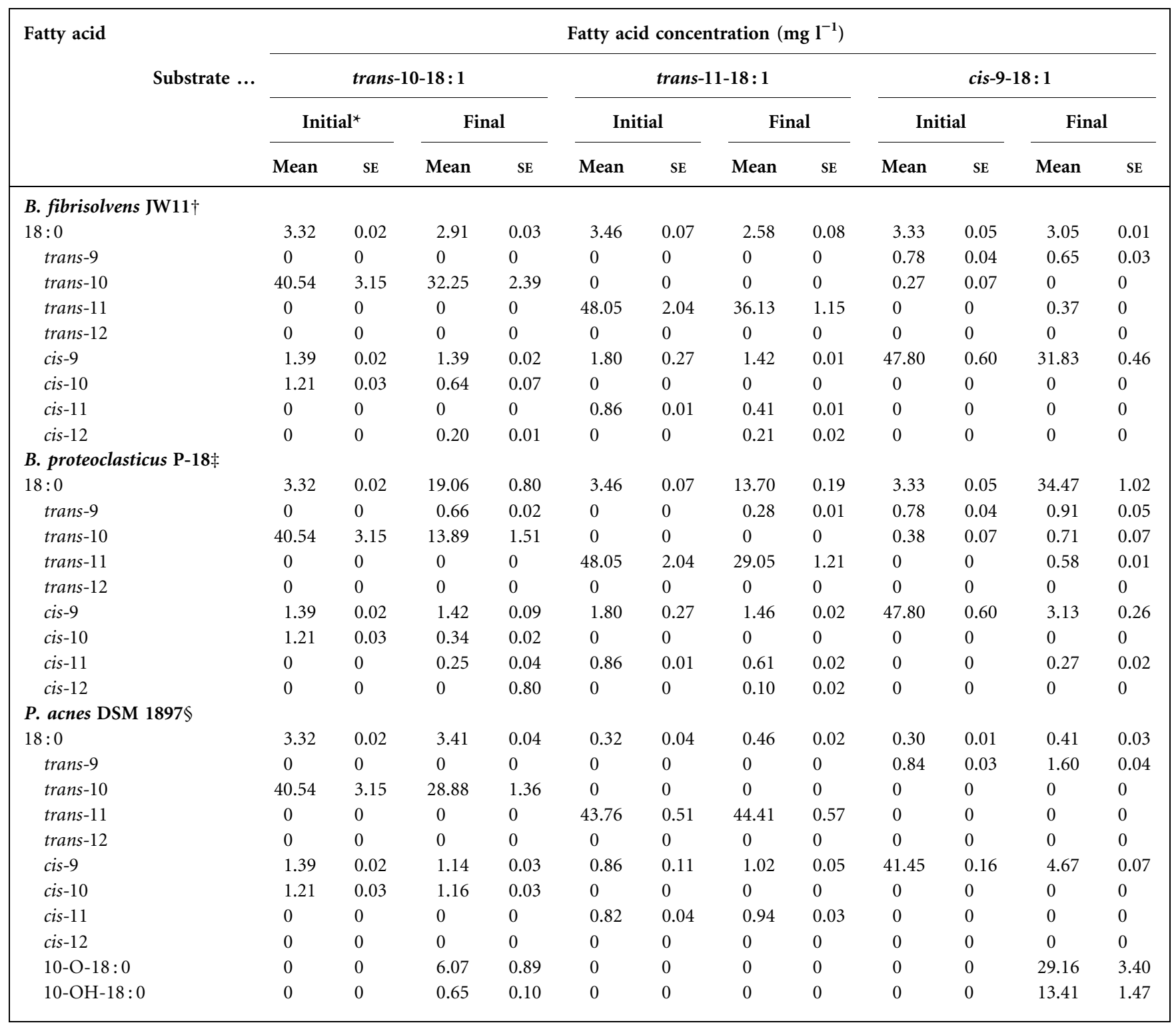

*Uninoculated medium.

$\dagger$ Final values determined in $24 \mathrm{~h}$ cultures, $n=3$.

$\$$ Final values determined in $30 \mathrm{~h}$ cultures, except cis-9-18:1, which was determined at $72 \mathrm{~h}, n=3$.

$\S$ Final values determined in $96 \mathrm{~h}$ cultures, $n=3$.

phase (Wallace et al., 2006). Even though the CLA substrates were found to be impure, the occurrence of other fatty acids in these materials was not considered to influence the main conclusions of the study.

The different positional and geometric isomers of CLA are similar chemically and typically difficult to separate from each other (Christie et al., 2001). They are also subject to racemization under relatively mild conditions (Christie et al., 2001). Thus, although impurities were present in the substrates used here, it would in practice be difficult to improve upon their quality. Note that the impurities were invariably geometric rather than positional isomers, and it is known that, for example, $B$. fibrisolvens produces several 9,11 geometric isomers, most likely by the same isomerization mechanism that converts linoleic acid to CLA (Kepler et al., 1966; Wallace et al., 2007). Thus, the reductases of these bacteria would typically be presented with several geometric isomers. Here, the trans-10,cis-12-18:2 preparation was heavily contaminated with trans-10,trans-12$18: 2$. It is possible that the contaminant inhibited the reduction of trans-10,cis-12-18:2 by $P$. acnes, but in view of the fact that no other CLA were reduced either, it seems more likely that $P$. acnes does not metabolize trans-10, cis- 
Table 4. Enrichment in products of metabolism of CLA isomers and $18: 1$ fatty acids by ruminal Butyrivibrio spp. and $P$. acnes DSM 1897 grown in deuterium oxide-enriched medium

Data were obtained from $24 \mathrm{~h}$ cultures for B. fibrisolvens, $30 \mathrm{~h}$ cultures for B. proteoclasticus with trans-10-18:1 and trans-11-18:1 and 72 $\mathrm{h}$ cultures with cis-9-18:1, and $96 \mathrm{~h}$ cultures for $P$. acnes; the enrichment of D in water was 0.374

\begin{tabular}{|c|c|c|c|c|c|c|}
\hline \multirow[t]{2}{*}{ Bacterium } & \multirow[t]{2}{*}{ Substrate } & \multirow[t]{2}{*}{ Product } & \multicolumn{2}{|c|}{$\begin{array}{c}\text { Enrichment in } \mathrm{M}+\mathbf{1} \\
(\mathrm{MPE})\end{array}$} & \multicolumn{2}{|c|}{$\begin{array}{c}\text { Enrichment in } \mathrm{M}+2 \\
(\mathrm{MPE})\end{array}$} \\
\hline & & & Mean & SE & Mean & SE \\
\hline \multirow[t]{5}{*}{ B. fibrisolvens } & cis-9,trans-11-18:2 & trans-11-18: 1 & 25.9 & 0.25 & 2.37 & 0.38 \\
\hline & trans-10, cis-12-18:2 & trans-10-18: 1 & 42.8 & 0.13 & 3.14 & 0.09 \\
\hline & trans-10,cis-12-18:2 & trans-12-18: 1 & 39.9 & 0.30 & 1.06 & 1.57 \\
\hline & trans -10, cis-12-18:2 & cis-12-18: 1 & 40.6 & 1.53 & -11.0 & 4.49 \\
\hline & trans-9,trans-11-18:2 & trans-11-18: 1 & 25.4 & 0.60 & -6.0 & 1.31 \\
\hline \multirow[t]{3}{*}{ B. proteoclasticus } & trans-10-18: 1 & $18: 0$ & 42.0 & 0.19 & 22.6 & 0.08 \\
\hline & trans-11-18: 1 & $18: 0$ & 39.9 & 0.18 & 23.8 & 0.50 \\
\hline & cis-9-18: 1 & $18: 0$ & 43.1 & 0.16 & 19.5 & 0.25 \\
\hline \multirow[t]{4}{*}{ P. acnes } & trans-10-18:1 & $10-\mathrm{O}-18: 0$ & 0 & 0 & 0 & 0 \\
\hline & trans-10-18: 1 & $10-\mathrm{OH}-18: 0^{*}$ & 51.2 & 1.34 & 27.1 & 2.28 \\
\hline & cis-9-18: 1 & $10-\mathrm{O}-18: 0$ & -4.6 & 4.84 & -1.5 & 1.01 \\
\hline & cis-9-18: 1 & $10-\mathrm{OH}-18: 0^{*}$ & 35.1 & 0.28 & -1.7 & 0.44 \\
\hline
\end{tabular}

${ }^{\star}$ Estimate based on enrichment calculated for the abundant ion fragment at $\mathrm{m} / \mathrm{z} 201$ owing to the lack of molecular ion.

12-18:2 further. The main uncertainty is with $B$. fibrisolvens, where trans-10-18:1 was the main product, but trans-12-18:1 and cis-12-18: 1 were also formed. It is impossible to say which 18:1 was derived from which CLA precursor. Otherwise, the results are not ambiguous.

The choice of initial fatty acid concentration is another important practical issue. If the concentration is too low, trace activities cannot be distinguished from significant ones and the results may be misleading. Many of the bacteria identified by Harfoot \& Hazlewood (1997), on the basis of the metabolism of low-concentration, radiolabelled substrates, to play a role in biohydrogenation actually have very little activity (Maia et al., 2007). On the other hand, high concentrations of polyunsaturated fatty acids (PUFAs) lead to inhibition of biohydrogenation, particularly the final step (Beam et al., 2000; Troegeler-Meynadier et al., 2003; Fievez et al., 2007). In our experience, concentrations of $200 \mathrm{mg} \mathrm{l}^{-1}$ and above of $18: 2$ and $18: 3$ fatty acids inhibit biohydrogenation. Such concentrations would be common in grazing animals (Dawson \& Hemington, 1974; Fievez et al., 2007). The concentration used here, $50 \mathrm{mg} \mathrm{l}^{-1}$, enables activity to be determined and most products to be identified, while not presenting most of the inhibitory problems associated with higher concentrations.

The first ruminal bacterium found to carry out biohydrogenation of linoleic acid was B. fibrisolvens (Polan et al., 1964). Further studies (Paillard et al., 2007; Maia et al., 2007) indicated that the high capacity to metabolize linoleic acid is associated entirely with the Butyrivibrio group, which includes the 18:0-producing B. proteoclasti- cus (Moon et al., 2008), previously named C. proteoclasticum (Wallace et al., 2006), or Fusocillus sp. (Kemp et al., 1975). These species produce mainly cis-9,trans-11-18:2 from linoleic acid, but also smaller concentrations of trans9,trans-11-18:2 (Kepler et al., 1966; Wallace et al., 2007). Here it is shown that both 9,11 geometric isomers of CLA are metabolized to trans-11-18:1 by $B$. fibrisolvens. Although the concentrations of cis-9,trans-11-18:2 and trans-10,cis-12-18:2 prevented growth of B. proteoclasticus, previous reports (Wallace et al., 2006; Maia et al., 2007) using lower fatty acid concentrations tend to suggest that B. proteoclasticus is capable of converting CLA to $18: 1$ fatty acids in the same manner as B. fibrisolvens. Furthermore, trans-10,cis-12-18:2, which is known to exert antilipogenic effects in lactating ruminants (Lock et al., 2006; Shingfield \& Griinari, 2007; Shingfield et al., 2009), is not metabolized further by the producing species, $P$. acnes, but is converted by Butyrivibrio spp. to a mixture of trans-10$18: 1$, trans-12-18:1 and cis-12-18:1. Early studies also demonstrated that trans-10,cis-12-18:2 is converted to trans-10-18:1 during incubation with pure cultures of $B$. fibrisolvens (Kepler et al., 1966).

The microbial ecology of biohydrogenation seems likely not to be as simple as was once thought. Although much effort has been expended in studying biohydrogenating bacteria, their biochemistry and microbial ecology, the correlation between biohydrogenation activity in the rumen, fatty acid composition of ruminal or duodenal digesta and microbial ecology has been disappointingly weak (Boeckaert et al., 2008; Kim et al., 2008), leading to some speculation that key species may not yet have been isolated, or indeed may be uncultivable (Boeckaert et al., 
2008; Kim et al., 2008). In particular, the species responsible for the changes in ruminal lipid metabolism resulting in trans-10-18:1 replacing trans-11-18:1 as the major intermediate remains unclear. Megasphaera elsdenii was identified as a possible candidate (Kim et al., 2002), but no M. elsdenii has been found to metabolize linoleic acid in our laboratory, and only isolates of $P$. acnes have been demonstrated to exhibit this activity. $P$. acnes is one of the less numerous ruminal species, and it is questionable whether alterations in the growth of this species alone can account for the changes in ruminal fatty acid outflow known to occur in lactating cows fed diets containing low proportions of forage, high levels of starch or lipid supplements rich in PUFAs (Shingfield \& Griinari, 2007). The present results do not resolve this issue, but they do illustrate the uniqueness and importance of bacteria such as $B$. proteoclasticus that are capable of metabolizing trans-10,cis-12-18:2 to $18: 0$ via trans-10-18:1. It had been shown previously (Hazlewood et al., 1976) that B. proteoclasticus converted trans-11- and cis-9-18:1 to $18: 0$. Here we demonstrate that trans-10-18:1 is also hydrogenated. Thus, $B$. proteoclasticus and possibly other bacteria that catalyse the conversion of $18: 1$ intermediates to $18: 0$ play a vital role in determining the supply of fatty acids available for absorption and subsequent incorporation into ruminant meat and milk.

The mass spectra of deuterated DMOX esters provide some clues about the mechanisms responsible for the reduction of cis and trans double bonds. For example, although the mass spectra were not definitive, the results are consistent with the conclusion of Rosenfeld \& Tove (1971) that the biohydrogenation of the cis-9 bond of cis-9,trans-11-18:2 occurs by a stereospecific cis addition to the $\mathrm{D}$ side of carbons 9 and 10. Metabolism of other CLA isomers has not been investigated previously. The novel information generated from this study indicates that the reduction of trans-9, trans-11-18:2 appears similar to that of cis-9,trans11-18:2, while the reduction of trans-10,cis-12-18:2 follows a different pattern, as highlighted by the higher incorporation of deuterium from $\mathrm{D}_{2} \mathrm{O}$. Rosenfeld \& Tove (1971) discovered that, when the cis-9 bond of cis-9,trans11-18:2 was biohydrogenated, more deuterium was found on the $\mathrm{C}$ atom distal to the trans bond than on the adjacent C. Incorporation of label indicated that the same is also true for the reduction of the cis-12 bond of trans-10,cis-12$18: 2$. However, enrichment from $\mathrm{D}_{2} \mathrm{O}$ was almost twice as high for the reduction of the cis-12 compared to the cis- 9 double bond.

The formation of 10-O-18:0 from trans-10-18:1 and cis$9-18: 1$ by $P$. acnes may provide an insight into the synthesis of saturated oxo-fatty acids that are known to be incorporated into bovine milk fat (Brechany \& Christie, 1992). Hudson et al. (1995) had already shown that hydration of oleic acid led to the formation of $10-\mathrm{OH}-18: 0$ in Selenomonas ruminantium and Enterococcus faecium. Further studies revealed that ruminal digesta of sheep and cows contained several strains capable of hydrating cis-9$18: 1$, the most numerous being isolates of Streptococcus bovis (Hudson et al., 2000). Incubations of cis-9-18: 1 with mixed rumen microbes resulted in the formation of 10 $\mathrm{OH}-18: 0$, with evidence that the hydroxyl group was further oxidized to yield 10-O-18:0 as a major end product (Jenkins et al., 2006). Several bacteria have been identified as capable of converting cis-9-18:1 to 10-O18:0, including Staphylococcus sp. (Lanser, 1993) and Flavobacterium sp. strain DS5 (Hou, 1994). The present data indicate that $P$. acnes is at least one bacterium in the rumen responsible for the hydration of cis-9-18:1 and further oxidation of 10-OH-18:0. P. acnes also metabolized trans-10-18:1 to $10-\mathrm{O}-18: 0$ via $10-\mathrm{OH}-18: 0$. Early studies have also demonstrated that an enzyme preparation from a pseudomonad converted trans-10-18:1 to $10-\mathrm{OH}-$ 18:0 (Mortimer \& Niehaus, 1972). However, labelling of 10-OH-18:0 formed from both 18:1 substrates during incubations with $P$. acnes suggests that the mechanism of hydration of the cis-9 bond involves the incorporation of one deuterium atom from water, while the hydration of trans-10-18:1 results in two deuterium atoms being incorporated.

It is also notable that $18: 0$ formed during metabolism of 18:1 fatty acids was labelled in $\mathrm{M}+2$, whereas $18: 1$ intermediates produced during the reduction of CLA isomers were not, which also suggests that the enzymic mechanisms are different. The latter mechanism may account for the ability of $B$. proteoclasticus, but no other known species, to reduce 18:1 fatty acids to $18: 0$ in the rumen. Morris (1970) concluded that the reduction of the cis bond of cis-9-18:1 was, like that of cis-9,trans-11-18:2, a stereospecific cis addition. Our data do not provide definitive information one way or the other on the mechanism responsible for the metabolism of $18: 1$ fatty acids, but the fact that all three gave the same pattern of $M+1 / M+2$ enrichments suggests that the same enzymic mechanism may be involved.

In conclusion, there are likely to be three systems for the metabolism of unsaturated fatty acids in ruminal biohydrogenating bacteria (Fig. 1) - one that reduces geometric isomers of 9,11 CLA to trans-11-18:1, another that reduces 10,12 geometric isomers of CLA to a mixture of 10- and 12-18:1 fatty acids, and a third, only found in $B$. proteoclasticus, that reduces a range of monoenoic fatty acids, including trans-10-18:1, to 18:0. Our data also indicate that $P$. acnes hydrates $18: 1$ substrates to yield 10 $\mathrm{O}-18: 0$ as an end product. To our knowledge, this is the first time that the mechanisms of reduction of PUFAs and $18: 1$ fatty acids in ruminal bacteria have been analysed in this way. The results inform us about a biochemical process that has a major influence on human health, via the fatty acid composition of ruminant-derived products (Scollan et al., 2001; Bauman et al., 2005) and possibly, by extrapolation, to the similar reactions that occur in the human colon (Devillard et al., 2007). 


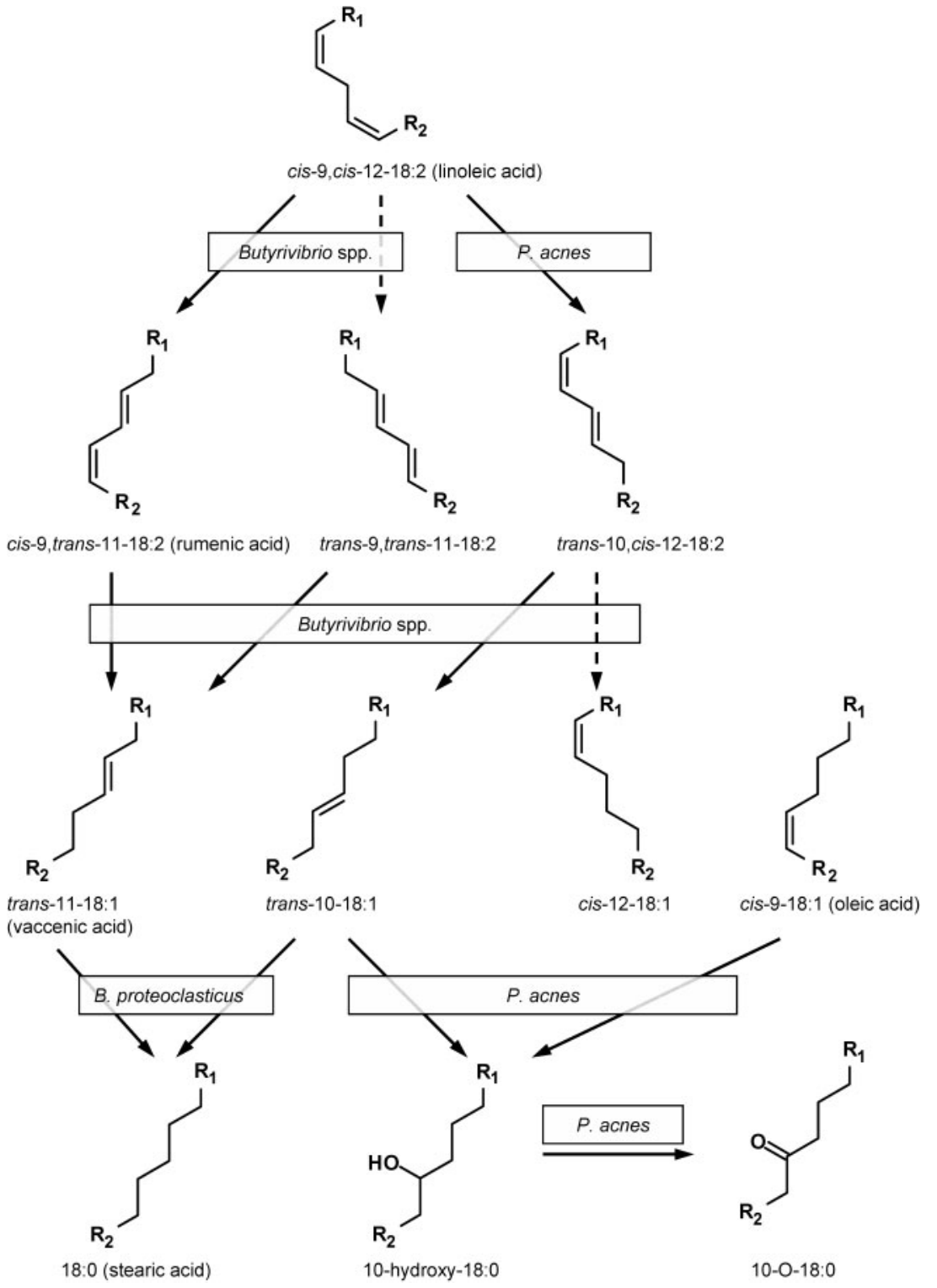

Fig. 1. Summary of our present understanding of the roles of Butyrivibrio spp. in general, $B$. proteoclasticum and $P$. acnes in the metabolism of dietary unsaturated fatty acids (linoleic and oleic acids) and their products. A dashed arrow denotes a minor route. The following observations should be considered alongside the flow chart. The fate of cis-12-18:1 is unknown. Butyrivibrio spp. other than $B$. proteoclasticum metabolize $18: 1$ fatty acids to products that have not been determined; the transformation occurs much less extensively than the conversion of $18: 1$ fatty acids to stearate by $B$. proteoclasticum. Butyrivibrio spp. form traces of other 9,11-18:2 isomers not shown here from linoleic acid.

\section{ACKNOWLEDGEMENTS}

The Rowett Institute of Nutrition and Health receives funding from the Rural and Environment Research and Analysis Directorate of the Scottish Government. We thank Frédéric Destaillats, Nestlé, Lausanne, for the gift of trans-10-18:1. We also thank David Brown, Eric Milne and Donna Wallace for technical assistance and expertise. Grietje Holtrop, Gerald Lobley, Wendy Russell and Vesa Toivonen offered invaluable advice on mass spectral and isotopic analysis, for which the authors are extremely grateful.

\section{REFERENCES}

Bauman, D. E., Lock, A. L., Corl, B. A., Ip, C., Salter, A. M. \& Parodi, P. M. (2005). Milk fatty acids and human health: potential role of conjugated linoleic acid and trans fatty acids. In Ruminant Physiology: Digestion, Metabolism and Impact of Nutrition on Gene Expression, Immunology and Stress, pp. 529-561. Edited by K. Serjrsen, T.
Hvelplund \& M. O. Nielsen. Wageningen, The Netherlands: Wageningen Academic Publishers.

Baumgard, L. H., Corl, B. A., Dwyer, D. A., Sæbø, A. \& Bauman, D. E. (2000). Identification of the conjugated linoleic acid isomer that inhibits milk fat synthesis. Am J Physiol Regul Integr Comp Physiol 278, R179-R184.

Beam, T. M., Jenkins, T. C., Moate, P. J., Kohn, R. A. \& Palmquist, D. L. (2000). Effects of amount and source of fat on the rates of lipolysis and biohydrogenation of fatty acids in ruminal contents. J Dairy Sci 83, 2564-2573.

Boeckaert, C., Vlaeminck, B., Fievez, V., Maignien, L., Dijkstra, J. \& Boon, N. (2008). Accumulation of trans C-18:1 fatty acids in the rumen after dietary algal supplementation is associated with changes in the Butyrivibrio community. Appl Environ Microbiol 74, 6923-6930.

Brechany, E. Y. \& Christie, W. W. (1992). Identification of the saturated oxo fatty acids in cheese. J Dairy Res 59, 57-64.

Campbell, I. M. (1974). Incorporation and dilution values - their calculation in mass spectrally stable isotope labeling experiments. Bioorg Chem 3, 386-397. 
Christie, W. W., Sébédio, J. L. \& Juanéda, P. (2001). A practical guide to the analysis of conjugated linoleic acid (CLA). Inform 12, 147-154.

Dawson, R. M. \& Hemington, N. (1974). Digestion of grass lipids and pigments in the sheep rumen. Br J Nutr 32, 327-340.

Devillard, E., McIntosh, F. M., Newbold, C. J. \& Wallace, R. J. (2006). Rumen ciliate protozoa contain high concentrations of conjugated linoleic acids and vaccenic acid, yet do not hydrogenate linoleic acid or desaturate stearic acid. Br J Nutr 96, 697-704.

Devillard, E., McIntosh, F. M., Duncan, S. H. \& Wallace, R. J. (2007). Metabolism of linoleic acid by human gut bacteria: different routes for biosynthesis of conjugated linoleic acid. J Bacteriol 189, 25662570 .

Fievez, V., Vlaeminck, B., Jenkins, T., Enjalbert, F. \& Doreau, M. (2007). Assessing rumen biohydrogenation and its manipulation in vivo, in vitro and in situ. Eur J Lipid Sci Technol 109, 740-756.

Folch, J., Lees, M. \& Sloane, G. H. (1957). A simple method for the isolation and purification of total lipids from animal tissues. $J$ Biol Chem 226, 497-509.

Harfoot, C. G. \& Hazlewood, G. P. (1997). Lipid metabolism in the rumen. In The Rumen Microbial Ecosystem, pp. 382-426. Edited by P. N. Hobson \& C. S. Stewart. London: Chapman \& Hall.

Hazlewood, G. P., Kemp, P., Lander, D. \& Dawson, R. M. C. (1976). C18 unsaturated fatty acid hydrogenation patterns of some rumen bacteria and their ability to hydrolyse exogenous phospholipid. $\mathrm{Br} \mathrm{J}$ Nutr 35, 293-297.

Hobson, P. N. (1969). Rumen bacteria. Methods Microbiol 3B, 133139.

Hou, C. T. (1994). Production of 10-ketostearic acid from oleic acid by Flavobacterium sp. strain Ds5 (Nrrl B-14859). Appl Environ Microbiol 60, 3760-3763.

Hudson, J. A., MacKenzie, C. A. \& Joblin, K. N. (1995). Conversion of oleic acid to 10-hydroxystearic acid by two species of ruminal bacteria. Appl Microbiol Biotechnol 44, 1-6.

Hudson, J. A., Cai, Y., Corner, R. J., Morvan, B. \& Joblin, K. N. (2000), Identification and enumeration of oleic acid and linoleic acid hydrating bacteria in the rumen of sheep and cows. J Appl Microbiol 88, 286-292.

Hungate, R. E. (1969). A roll tube method for cultivation of strict anaerobes. Methods Microbiol 3B, 117-132.

Huws, S. A., Kim, E. J., Kingston-Smith, A. H., Lee, M. R. F., Muetzel, S. M., Cookson, A. R., Newbold, C. J., Wallace, R. J. \& Scollan, N. D. (2009). Rumen protozoa are rich in polyunsaturated fatty acids due to the ingestion of chloroplasts. FEMS Microbiol Ecol 69, 461-471.

Jenkins, T. C., AbuGhazaleh, A. A., Freeman, S. \& Thies, E. J. (2006). The production of 10-hydroxystearic and 10-ketostearic acids is an alternative route of oleic acid transformation by the ruminal microbiota in cattle. J Nutr 136, 926-931.

Jenkins, T. C., Wallace, R. J., Moate, P. J. \& Mosley, E. E. (2008). Recent advances in biohydrogenation of unsaturated fatty acids within the rumen microbial ecosystem. J Anim Sci 86, 397-412.

Kemp, P., White, R. W. \& Lander, D. J. (1975). The hydrogenation of unsaturated fatty acids by five bacterial isolates from the sheep rumen, including a new species. J Gen Microbiol 90, 100-114.

Kepler, C. R., Hirons, K. P., McNeill, J. J. \& Tove, S. B. (1966), Intermediates and products of the biohydrogenation of linoleic acid by Butyrivibrio fibrisolvens. J Biol Chem 241, 1350-1354

Kim, Y. J., Liu, R. H., Rychlik, J. L. \& Russell, J. B. (2002). The enrichment of a ruminal bacterium (Megasphaera elsdenii YJ-4) that produces the trans-10,cis-12 isomer of conjugated linoleic acid. J Appl Microbiol 92, 976-982.
Kim, E. J., Huws, S. A., Lee, M. R. F., Wood, J. D., Muetzel, S. M., Wallace, R. J. \& Scollan, N. D. (2008). Fish oil increases the duodenal flow of long chain polyunsaturated fatty acids and trans-11 18:1 and decreases 18:0 in steers via changes in the rumen bacterial community. J Nutr 138, 889-896.

Lanser, A. C. (1993). Conversion of oleic acid to 10-ketostearic acid by a Staphylococcus species. J Am Oil Chem Soc 70, 543-545.

Lock, A. L., Teles, B. M., Perfield, J. W., Bauman, D. E. \& Sinclair, L. A. (2006). A conjugated linoleic acid supplement containing trans-10, cis-12 reduces milk fat synthesis in lactating sheep. J Dairy Sci $\mathbf{8 9}$, 1525-1532.

Maia, M. R. G., Chaudhary, L. C., Figueres, L. \& Wallace, R. J. (2007). Metabolism of polyunsaturated fatty acids and their toxicity to the microflora of the rumen. Antonie Van Leeuwenhoek 91, 303-314.

Mensink, R. P., Zock, P. L., Kester, A. D. \& Katan, M. B. (2003). Effects of dietary fatty acids and carbohydrates on the ratio of serum total to HDL cholesterol and on serum lipids and apolipoproteins: a metaanalysis of 60 controlled trials. Am J Clin Nutr 77, 1146-1155.

Moon, C. D., Pacheco, D. M., Kelly, W. J., Leahy, S. C., Li, D., Kopecny, J. \& Attwood, G. T. (2008). Reclassification of Clostridium proteoclasticum as Butyrivibrio proteoclasticus comb. nov., a butyrate-producing ruminal bacterium. Int J Syst Evol Microbiol 58, 2041-2045.

Morris, L. J. (1970). Mechanisms and stereochemistry in fatty acid metabolism - Fifth Colworth Medal Lecture. Biochem J 118, 681-693.

Mortimer, C. E. \& Niehaus, W. G. (1972). Enzymatic isomerization of oleic acid to trans- $\Delta^{10}$-octadecenoic acid. Biochem Biophys Res Commun 49, 1650-1656.

Nam, I. S. \& Garnsworthy, P. C. (2007). Biohydrogenation of linoleic acid by rumen fungi compared with rumen bacteria. J Appl Microbiol 103, 551-556.

Nugent, A. P. (2004). The metabolic syndrome. Nutr Bull 29, 36-43. Paillard, D., McKain, N., Chaudhary, L. C., Walker, N. D., Pizette, F., Koppova, I., McEwan, N. R., Kopečný, J., Vercoe, P. E. \& other authors (2007). Relation between phylogenetic position, lipid metabolism and butyrate production by different Butyrivibrio-like bacteria from the rumen. Antonie Van Leeuwenhoek 91, 417-422.

Pariza, M. W. (2004). Perspective on the safety and effectiveness of conjugated linoleic acid. Am J Clin Nutr 79, 1132S-1136S.

Polan, C. E., McNeill, J. J. \& Tove, S. B. (1964). Biohydrogenation of unsaturated fatty acids by rumen bacteria. J Bacteriol 88, 1056-1064.

Rosenfeld, I. S. \& Tove, S. B. (1971). Biohydrogenation of unsaturated fatty acids. VI. Source of hydrogen and stereospecificity of reduction. J Biol Chem 246, 5025-5030.

Sæbø, A., Sæbø, P., Griinari, J. M. \& Shingfield, K. J. (2005). Effect of abomasal infusion of geometric isomers of 10,12 conjugated linoleic acid on milk fat synthesis in dairy cows. Lipids 40, 823-832.

Scollan, N. D., Dhanoa, M. S., Choi, N. J., Maeng, W. J., Enser, M. \& Wood, J. D. (2001). Biohydrogenation and digestion of long chain fatty acids in steers fed on different sources of lipid. J Agric Sci Camb 136, 345-355.

Shingfield, K. J. \& Griinari, J. M. (2007). Role of biohydrogenation intermediates in milk fat depression. Eur J Lipid Sci Technol 109, 799-816.

Shingfield, K. J., Chilliard, Y., Toivonen, V., Kairenius, P. \& Givens, D. I. (2008). Trans fatty acids and bioactive lipids in ruminant milk. In Bioactive Components of Milk. Adv Exp Med Biol 606, 3-65.

Shingfield, K. J., Sæbø, A., Sæbø, P.-C., Toivonen, V. \& Griinari, J. M. (2009). Effect of abomasal infusions of a mixture of octadecenoic acids on milk fat synthesis in lactating cows. J Dairy Sci 92, 43174329. 
Troegeler-Meynadier, A., Nicot, M. C., Bayourthe, C., Moncoulon, R. \& Enjalbert, F. (2003). Effects of $\mathrm{pH}$ and concentrations of linoleic and linolenic acids on extent and intermediates of ruminal biohydrogenation in vitro. J Dairy Sci 86, 4054-4063.

Wallace, R. J. \& Brammall, M. L. (1985). The role of different species of rumen bacteria in the hydrolysis of protein in the rumen. $J$ Gen Microbiol 131, 821-832.

Wallace, R. J., Chaudhary, L. C., McKain, N., McEwan, N. R., Richardson, A. J., Vercoe, P. E., Walker, N. D. \& Paillard, D. (2006). Clostridium proteoclasticum: a ruminal bacterium that forms stearic acid from linoleic acid. FEMS Microbiol Lett 265, 195-201.
Wallace, R. J., McKain, N., Shingfield, K. J. \& Devillard, E. (2007). Isomers of conjugated linoleic acids are synthesized via different mechanisms in ruminal digesta and bacteria. J Lipid Res 48, 2247-2254.

Waşowska, I., Maia, M. R. G., Niedzwiedzka, K. M., Czauderna, M., Ramalho Ribeiro, J. M. C., Devillard, E., Shingfield, K. J. \& Wallace, R. J. (2006). Influence of fish oil on ruminal biohydrogenation of C18 unsaturated fatty acids. Br J Nutr 95, 1199-1211.

World Health Organization (2003). Diet, nutrition and prevention of chronic diseases. WHO Technical Report Series 916, 1-148.

Edited by: H. L. Drake 